\title{
Lack of progress in cardiogenic shock: lessons from the GUSTO trials
}

\author{
V. Menon 1 , J. S. Hochman ${ }^{1}$, A. Stebbins ${ }^{2}$, M. Pfisterer ${ }^{3}$, J. Col ${ }^{4}$, R. D. Anderson ${ }^{2}$, \\ D. Hasdai ${ }^{5}$, D. R. Holmes $\mathrm{Jr}^{5}$, E. R. Bates ${ }^{6}$, E. J. Topol ${ }^{7}$, R. M. Califf ${ }^{2}$ and \\ E. M. Ohman ${ }^{2}$ for the GUSTO Investigators
}

\author{
${ }^{1}$ Division of Cardiology, St. Luke's-Roosevelt Hospital Center, Columbia University, New York, NY, U.S.A.; \\ ${ }^{2}$ Division of Cardiology, Duke University Medical Center, Durham, NC, U.S.A.; ${ }^{3}$ Division of Cardiology, \\ University Hospital, Basel, Switzerland; ${ }^{4}$ Division of Cardiology, Cliniques Universitaires, Brussels, Belgium; \\ ${ }^{5}$ Division of Cardiology, Mayo Clinic, Rochester, MN, U.S.A.; ${ }^{6}$ Division of Cardiology, University of Michigan \\ Medical Center, Ann Arbor, MI, U.S.A.; ${ }^{7}$ Division of Cardiology, Cleveland Clinic Foundation, Cleveland, OH, \\ U.S.A.
}

\begin{abstract}
Aims We used the GUSTO-I and GUSTO-III databases to evaluate our performance in treating cardiogenic shock patients over much of the 1990s.
\end{abstract}

Methods and Results GUSTO-I (1990-1993) and GUSTO-III (1995-1997) prospectively identified all patients with cardiogenic shock complicating acute myocardial infarction. Demographics, clinical presentation and outcomes for cardiogenic shock patients in the two trials were compared. Only patients enrolled with cardiogenic shock in countries common to both trials were included in these analysis. The 695 patients with cardiogenic shock in GUSTO-III were compared with the 2814 patients with cardiogenic shock in GUSTO-I. GUSTO-III patients were older $(P=0 \cdot 0001)$ and more likely to be diabetic $(P=0 \cdot 009)$ and hypertensive $(P=0.025)$. They had a higher Killip class $(P=0 \cdot 002)$ and significantly greater index anterior infarction than cardiogenic shock patients enrolled in GUSTO-I. Time to treatment, presentation heart rate, and diastolic blood pressure were similar; however, systolic blood pressure at presentation was higher among GUSTO-III patients $(P=0 \cdot 002)$. Rates of coronary angiography, pulmonary artery catheterization, and mechanical ventilation declined in GUSTO-III compared with GUSTO-I $(P=0 \cdot 001)$; rates of angioplasty and bypass surgery were similar. Cardiogenic shock mortality in GUSTO-III was significantly higher than in GUSTO-I (62 vs 54\%, $P=0.001$ ), as were rates of reinfarction (14 vs $11 \%, P=0.013)$ and recurrent ischaemia ( 35 vs $27 \%, P=0 \cdot 00001$ ). Mortality at non-U.S. sites (68 and 64\%) was higher than at U.S. sites (53 and $50 \%$ ) in both GUSTO-I and GUSTO-III studies, respectively. Angioplasty, bypass surgery, and balloon pump rates were lower for non-U.S. patients.

Conclusions Cardiogenic shock continues to be associated with high mortality in thrombolytic-treated patients. Lower mortality observed in the U.S.A. supports consideration for percutaneous and surgical revascularization. (Eur Heart J 2000; 21: 1928-1936, doi:10.1053/euhj.2000. 2240)

(C) 2000 The European Society of Cardiology

Key Words: shock, thrombolysis, myocardial infarction, mortality.

See page 1903 for the Editorial comment on this paper

\section{Introduction}

The capacity to achieve early, complete and sustained reperfusion $^{[1-3]}$ after ST-elevation acute myocardial infarction has dramatically improved patient outcomes

Manuscript submitted 4 April 2000, and accepted 5 April 2000.

Correspondence: Venu Menon, MD, FACC, Assistant DirectorCardiac Research, Cardiac Study Center, St. Luke's-Roosevelt Hospital Center, 1111 Amsterdam Avenue, New York, NY 10025, U.S.A. in the reperfusion era. This early salvage of jeopardized myocardium appears to have led to a decline in the overall incidence of cardiogenic shock ${ }^{[4,5]}$. The prognosis for patients who present with or develop this complication, however, remains dismal. Cardiogenic shock remains the most common cause of in-hospital mortality following myocardial infarction. Despite an incidence of $7 \cdot 2 \%$ in GUSTO-I, it accounted for $58 \%$ of the overall deaths observed at 30 days $^{[6]}$.

The past decade has seen dramatic strides in our understanding of acute coronary syndromes. This 
has led to novel diagnostic and treatment strategies that have rapidly evolved from bench to bedside. Consequently, prognosis and outcomes for the universe of patients with acute ischaemic events has undoubtedly improved. It is less clear, however, whether outcomes are changing for the cohort with cardiogenic shock. In this context, a majority of early trials testing thrombolytic therapy selectively excluded patients with cardiogenic shock ${ }^{[7]}$. GUSTO-I (1990-93 $)^{[6]}$ and GUSTO-III $(1995-97)^{[8]}$ were amongst notable exceptions ${ }^{[9,10]}$. Patients with cardiogenic shock were prospectively identified and not excluded from these two trials. This combined data set of over 3000 patients with cardiogenic shock enables us to review our performance with this complication over much of the last decade.

\section{Methods}

The results of GUSTO-I and GUSTO-III have been previously published ${ }^{[1,8]}$. GUSTO-I was a prospective, randomized, thrombolytic mega-trial that enrolled 41021 patients with chest pain $\geq 20$ min but $<6 \mathrm{~h}$ with typical electrocardiographic abnormalities. Enrolled patients were randomized to receive one of four intravenous thrombolytic strategies: (1) streptokinase (Kabikinase, Kabi Vitrum, Sweden), 1.5 million U given over $1 \mathrm{~h}$ with subcutaneous $12500 \mathrm{U}$ of heparin twice daily beginning $4 \mathrm{~h}$ after streptokinase; (2) streptokinase, 1.5 million $U$ given over $1 \mathrm{~h}$ with intravenous heparin (5000-U bolus and infusion at $1000 \mathrm{U} . \mathrm{h}^{-1}$ ), adjusted to achieve an activated partial thromboplastin time (aPTT) of 60-85 s; (3) accelerated tissue-plasminogen activator (t-PA) (Genentech, San Francisco), given as a $15 \mathrm{mg}$ bolus, $0.75 \mathrm{mg} . \mathrm{kg}^{-1}$ body weight over $30 \mathrm{~min}$ (up to $50 \mathrm{mg}$ ) and $0.5 \mathrm{mg} \cdot \mathrm{kg}^{-1}$ (up to $35 \mathrm{mg}$ ) over the next hour with intravenous heparin; and (4) combined t-PA $\left(1.0 \mathrm{mg} . \mathrm{kg}^{-1}\right.$ over $60 \mathrm{~min}$, not to exceed $90 \mathrm{mg}$ with $10 \%$ as bolus) given with streptokinase (1 million $U$ over $60 \mathrm{~min}$ ) with intravenous heparin.

GUSTO-III enrolled 15059 patients who presented within $6 \mathrm{~h}$ of symptom onset with ST-segment elevation or bundle branch block. Patients were then randomized in a 2:1 ratio to receive reteplase (Boehringer Mannheim, Gaithersburg, MD, U.S.A. and Mannheim, Germany), in two bolus doses of $10 \mathrm{MU}$ each given $30 \mathrm{~min}$ apart, or an accelerated infusion of alteplase (Genentech, South San Francisco, CA, U.S.A. and Boehringer Ingelheim, Ingelheim, Germany), up to $100 \mathrm{mg}$ infused over $90 \mathrm{~min}$. Concomitant heparin was administered with a 5000-U bolus of heparin followed by an infusion of $1000 \mathrm{U} . \mathrm{h}^{-1}$. The initial rate of heparin was reduced to $800 \mathrm{U} . \mathrm{h}^{-1}$ for patients who weighed $<80 \mathrm{~kg}$ and adjusted to maintain an aPTT of $50-70 \mathrm{~s}$ in all patients ${ }^{[11]}$.

Patients with cardiogenic shock were prospectively identified in both trials. Cardiogenic shock was defined as systolic blood pressure $<90 \mathrm{mmHg}$ for at least $1 \mathrm{~h}$ that was not responsive to fluid resuscitation alone, thought to be secondary to cardiac dysfunction, and associated with signs of hypoperfusion, or a cardiac index $<2 \cdot 21 . \mathrm{min}^{-1} \cdot \mathrm{m}^{-2}$. Patients in whom systolic blood pressure increased to $>90 \mathrm{mmHg}$ within $1 \mathrm{~h}$ after administration of positive inotropic agents were still classified as having cardiogenic shock. The decision to place a pulmonary artery catheter was made by the attending physician at the local site. Reinfarction was defined by the presence of two or more of the following criteria: (1) recurrent ischaemic symptoms lasting $>15$ min; (2) new ST-T wave changes or new Q waves; (3) a second elevation in cardiac enzyme levels to above the normal upper limit, or a further $20 \%$ if already over the normal upper limit; and (4) angiographic reocclusion of a previously patent infarct-related artery. Recurrent ischaemia was defined as symptoms (chest discomfort, arm pain, jaw pain), ECG changes, or heart failure thought by the physician to represent myocardial ischaemia.

\section{Statistical analysis}

For the purpose of this report, analysis was restricted to enrolling countries that participated in both clinical trials (Fig. 1). Selected baseline characteristics and clinical outcomes for patients with cardiogenic shock were compared for the two trials. Multivariate logistic models were used to assess the importance of GUSTO-I versus GUSTO-III shock rates over and above the baseline characteristics found to be statistically significant in predicting 30-day mortality ${ }^{[12]}$. These co-variates include age, systolic blood pressure, infarct location and heart rate. Further, the mortality for patients receiving frontloaded t-PA in GUSTO-III was compared with that in the t-PA-treated group in GUSTO-I. Mortality rates for the subgroups of patients receiving angioplasty, bypass surgery, and intra-aortic balloon counterpulsation in the two studies were also compared. A chi-square test was used to analyse differences for discrete variables, and Wilcoxon rank sum scores were generated for comparison of continuous variables. Continuous data are summarized as medians with the 25 th and 75 th percentiles unless otherwise stipulated. All tests for significance were two-tailed.

Countries common to GUSTO-III and GUSTO-I were placed into two geographical groups: non-U.S. and U.S. Non-U.S. comprised Canada, Australia, New Zealand and countries in Europe that took part in both clinical trials. The frequency of cardiogenic shock, treatment procedures and outcomes in these geographical locales were analysed.

\section{Results}

\section{Incidence of cardiogenic shock and patient profile}

Overall $5 \cdot 5 \%(695 / 12572)$ of patients in GUSTO-III and $7 \cdot 4 \%(2814 / 37892)$ of patients in GUSTO-I had 

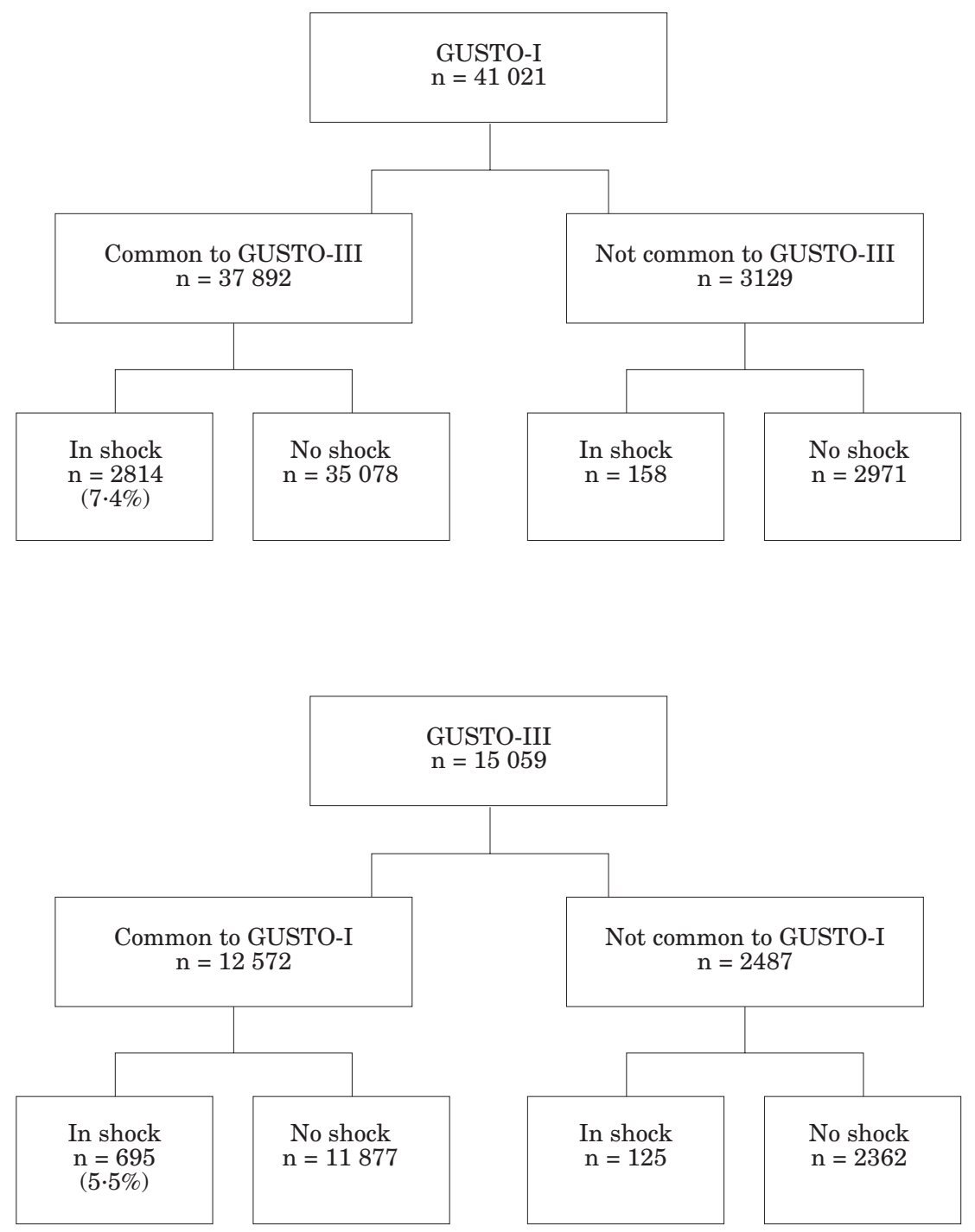

Figure 1 Only patients enrolled in countries common to both trials were considered for this study. The incidence of cardiogenic shock was 2814/37 892 $(7 \cdot 4 \%)$ in GUSTO-I and 695/12 $572(5 \cdot 5 \%)$ in GUSTO-III.

cardiogenic shock in countries common to both trials $(P=0.001)$. The proportion of patients with cardiogenic shock enrolled in the U.S.A. was 67\% (1891/2814) in GUSTO-I but only 39\% (271/695) in GUSTO-III. The incidence of cardiogenic shock in the U.S.A. decreased from $8 \cdot 2 \%(1891 / 23105)$ in GUSTO-I to $5 \cdot 7 \%(271 /$ $4774)$ in GUSTO-III $(P=0 \cdot 001)$. The incidence of cardiogenic shock outside the U.S.A. also decreased, but to a lesser extent - from $6 \cdot 2 \%$ in GUSTO-I (923/14 787) to $5 \cdot 4 \%(424 / 7828), P=0 \cdot 013)$.

Table 1 outlines the demographic profile of patients with cardiogenic shock in the two trials. Cardiogenic shock patients in GUSTO-III were significantly older than their counterparts in GUSTO-1 (median age 70.8 vs $68 \cdot 2$ years, $P=0 \cdot 0001)$, and had more diabetes $(23$ vs $19 \%, P=0.009$ ), hypertension (48 vs $44 \%, P=0.025$ ), previous myocardial infarction (28 vs $25 \%, P=0.059)$ and less history of previous angina (42 vs $51 \%$,
$P=0 \cdot 001)$. Both groups were $63 \%$ male and had similar baseline rates of hypercholesterolaemia, current smoking, prior bypass surgery and prior angioplasty. Patients with cardiogenic shock in GUSTO-III had more index anterior wall infarction (60 vs $50 \%, P=0.001)$. Time to treatment with thrombolysis was similar in both study groups.

\section{Clinical and haemodynamic presentation}

Table 2 illustrates the Killip class and haemodynamic findings at study entry. Presentation Killip class for cardiogenic shock patients was significantly higher in GUSTO-III than in GUSTO-I $(P=0 \cdot 002)$. Although the heart rate and diastolic blood pressure at presentation were similar, systolic blood pressure was statistically 
Table 1 Profile of patients with cardiogenic shock enrolled in GUSTO-I and GUSTO-III

\begin{tabular}{lccc}
\hline & GUSTO-I & GUSTO-III & $P$ value \\
\hline n (overall) & 2814 & 695 & \\
n (U.S.A.) & $1891(67 \%)$ & $271(39 \%)$ & \\
Age (years) & $68(60,75)$ & $71(61,77)$ & $0 \cdot 0001$ \\
Males & $1775(63 \%)$ & $434(63 \%)$ & $0 \cdot 758$ \\
Weight (kg) & $75(65,85)$ & $75(65,85)$ & $0 \cdot 684$ \\
Height (cm) & $170(163,177)$ & $170(162,176)$ & $0 \cdot 148$ \\
Hypertension & $1216(44 \%)$ & $335(49 \%)$ & $0 \cdot 025$ \\
Diabetes & $522(19 \%)$ & $160(23 \%)$ & $0 \cdot 009$ \\
Hypercholesterolaemia & $794(31 \%)$ & $223(33 \%)$ & $0 \cdot 231$ \\
Current smokers & $943(34 \%)$ & $208(31 \%)$ & $0 \cdot 220$ \\
Former smokers & $1688(60 \%)$ & $256(37 \%)$ & $0 \cdot 001$ \\
Previous angina & $1179(42 \%)$ & $355(51 \%)$ & $0 \cdot 001$ \\
Prior myocardial infarction & $690(25 \%)$ & $196(28 \%)$ & $0 \cdot 059$ \\
Previous angioplasty & $100(4 \%)$ & $30(4 \%)$ & $0 \cdot 356$ \\
Previous bypass surgery & $188(7 \%)$ & $36(5 \%)$ & $0 \cdot 138$ \\
Time to treatment (h) & $2 \cdot 8(2 \cdot 0,4 \cdot 0)$ & $2 \cdot 8(1 \cdot 8,3 \cdot 8)$ & $0 \cdot 099$ \\
Index anterior infarction & $1405(50 \%)$ & $414(60 \%)$ & $0 \cdot 001$ \\
& & & \\
\hline
\end{tabular}

*Presented as median (25th, 75th percentiles). Presented as numbers (percentages) except where indicated.

Table 2 Haemodynamics at study entry

\begin{tabular}{lccr}
\hline & GUSTO-I & GUSTO-III & $P$ value \\
\hline$n$ & 2814 & 695 & $0 \cdot 002$ \\
Systolic BP (mmHg)* & $115(98,131)$ & $119(100,140)$ & $0 \cdot 930$ \\
Diastolic BP (mmHg)* & $70(60,82)$ & $70(60,84)$ & $0 \cdot 002$ \\
Killip class on entry & $63 \cdot 1 \%$ & $57 \cdot 4 \%$ & $24 \cdot 9 \%$ \\
Killip class I & $20 \cdot 8 \%$ & $8 \cdot 3 \%$ & $9 \cdot 4 \%$ \\
Killip class II & $5 \cdot 5 \%$ & $81(65,100)$ & $0 \cdot 092$ \\
Killip class III & $10 \cdot 6 \%$ & & \\
Killip class IV & $80(66,96)$ & & \\
Heart rate (beats . min & $-1)^{*}$ & & \\
\hline
\end{tabular}

*Presented as median (25th, 75th percentile). Presented as numbers (percentages) except where indicated.

higher for cardiogenic shock patients enrolled in GUSTO-III.

\section{Timing, therapy and in-hospital management}

The median time from index myocardial infarction to development of cardiogenic shock was comparable: $7 \cdot 5$ $(3 \cdot 7,38 \cdot 3) \mathrm{h}$ in GUSTO-III versus $7 \cdot 8(3 \cdot 2,32 \cdot 0) \mathrm{h}$ in GUSTO-I. The median door to needle time $(1.00 \mathrm{~h})$ and median time from symptom onset to treatment $(2 \cdot 8 \mathrm{~h})$ for patients with cardiogenic shock were also unchanged from GUSTO-I to GUSTO-III.

Procedure utilization for cardiogenic shock subjects in GUSTO-III and GUSTO-I are illustrated in Fig. 2. The use of coronary angiography (39 vs $47 \%, P=0.001$ ), pulmonary artery catheter ( 30 vs $46 \%, P \leq 0.001$ ), and mechanical ventilation (41 vs $48 \%, P=0.001)$ declined significantly in GUSTO-III compared with GUSTO-I. The use of intra-aortic balloon counterpulsation support
(24 vs $26 \%, P=0 \cdot 496$ ) remained similar in GUSTO-III and GUSTO-I, as did the overall incidence of bypass surgery (11 vs 12\%) and angioplasty of the infarct-related artery (19 vs $20 \%$ ).

Procedural rates for non-U.S. and U.S. patients in GUSTO-I and GUSTO-III are given in Table 3. Rates of coronary angiography increased significantly in the U.S.A. between GUSTO-I and GUSTO-III (58\% vs $66 \% . P=0 \cdot 015$ ), while remaining static at non-U.S. sites ( $26 \%$ vs $22 \%, P=0 \cdot 119$ ). The proportion of U.S. patients in GUSTO-I undergoing angioplasty was 484/1891 $(26 \%)$ which increased to $87 / 270(32 \%)$ in GUSTO-III $(P=0.024)$. The rates for bypass surgery at U.S. sites in GUSTO-I and GUSTO-III were 295/1873 (16\%) and $49 / 271(18 \%)$, respectively $(P=0 \cdot 328)$. In contrast, the rates of angioplasty (10 vs $8 \%, P=0 \cdot 204)$ and bypass surgery $(7 \%$ vs $5 \%, P=0 \cdot 117)$ in GUSTO-III and GUSTO-I, respectively, were low in non-U.S. centres and did not increase with time. While rates of intraaortic balloon counterpulsation ( 47 vs $35 \%, P=0 \cdot 001$ ) 


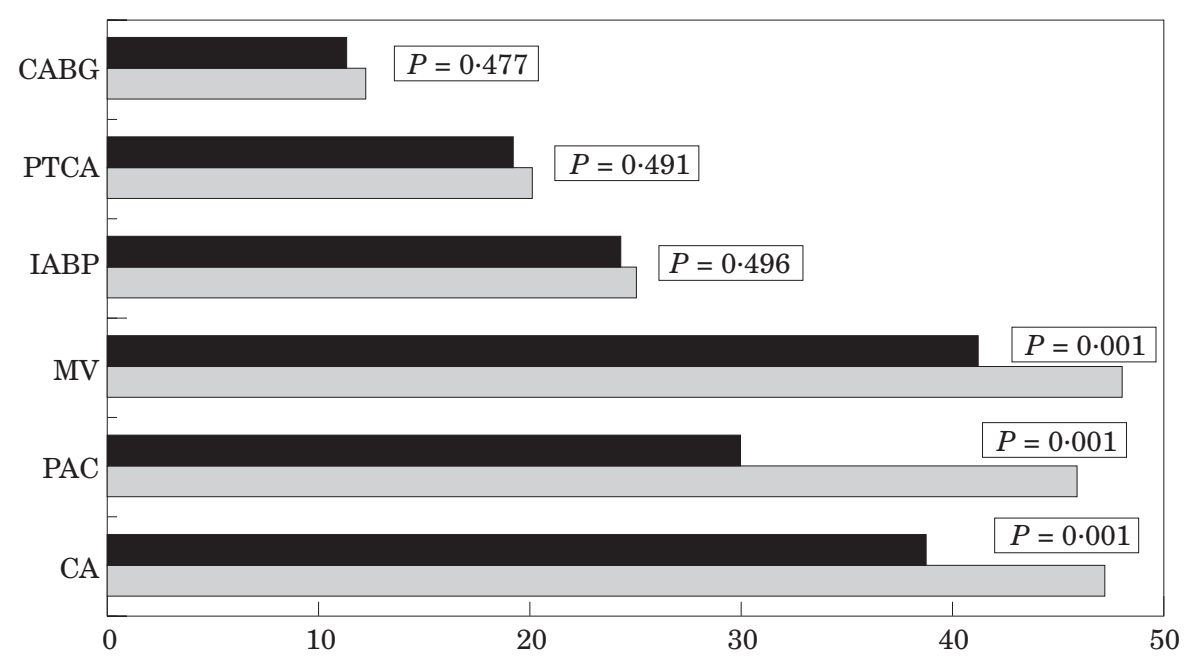

Figure 2 The rates of coronary angiography and pulmonary artery catheterization were significantly decreased in GUSTO-III ( $\square$ ) compared with GUSTO-I ( $\square$ ). Overall revascularization rates were comparable. $\mathrm{CABG}=$ coronary artery bypass surgery; $\mathbf{P T C A}=$ percutaneous transluminal coronary angioplasty; IABP = intra-aortic balloon counterpulsation; $\mathrm{MV}=$ mechanical ventilation; $\mathbf{P A C}=$ pulmonary artery catheterization; $\mathbf{C A}=$ coronary angiography.

Table 3 Rates of in-hospital procedures in cardiogenic shock patients in GUSTO-I and GUSTO-III based on U.S.Inon-U.S. location

\begin{tabular}{lcccccc}
\hline & $\begin{array}{c}\text { G-I U.S. } \\
(\% ; \mathrm{n}=1891)\end{array}$ & $\begin{array}{c}\text { G-III U.S. } \\
(\% ; \mathrm{n}=271)\end{array}$ & $P$ & $\begin{array}{c}\text { G-I non-U.S. } \\
(\% ; \mathrm{n}=923)\end{array}$ & $\begin{array}{c}\text { G-III non-U.S. } \\
(\% ; \mathrm{n}=424)\end{array}$ & $P$ \\
\hline Coronary angiography & 58 & 66 & $0 \cdot 015$ & 26 & 22 & $0 \cdot 119$ \\
Angioplasty, IRA & 26 & 32 & $0 \cdot 030$ & 8 & 10 & $0 \cdot 180$ \\
Angioplasty, non-IRA & 1 & 2 & $0 \cdot 082$ & $0 \cdot 3$ & 1 & $0 \cdot 144$ \\
Bypass surgery & 16 & 18 & $0 \cdot 328$ & 5 & 7 & $0 \cdot 117$ \\
Transvenous pacing & 32 & 24 & $0 \cdot 011$ & 17 & 14 & $0 \cdot 210$ \\
PAC & 57 & 46 & $0 \cdot 001$ & 23 & 19 & $0 \cdot 076$ \\
Mechanical ventilation & 54 & 53 & $0 \cdot 744$ & 34 & 33 & $0 \cdot 678$ \\
IABP & 35 & 47 & $0 \cdot 001$ & 7 & 10 & $0 \cdot 043$ \\
\hline
\end{tabular}

G-I=GUSTO-I; G-III=GUSTO-III; IRA=infarct related artery; PAC=pulmonary artery catheterization; IABP = intra-aortic balloon counterpulsation.

and mechanical ventilation (53 vs $54 \%, P=0 \cdot 744)$ remained high in the U.S.A. in GUSTO-III and GUSTO-I, respectively, they remained infrequently utilized at non-U.S. centres (intra-aortic balloon counterpulsation 10 vs $7 \%, P=0 \cdot 043$, ventilation $33 \%$ vs $34 \%$, $P=0.678$ ). A decline in the use of pulmonary artery catheterization was seen in both non-U.S. and U.S. centres. A decline in the overall use of transvenous pacing was also observed which mirrored a decline in the incidence of second- and third-degree atrioventricular block (28\% in GUSTO-I to $20 \%$ in GUSTO-III).

\section{Outcomes}

Table 4 compares overall mortality rates with cardiogenic shock in GUSTO-I and GUSTO-III. Thirty-day mortality for patients with cardiogenic shock was significantly higher in GUSTO-III than GUSTO-I (62 vs 54\%,
$P=0.001)$. This difference persisted at 1 year (69 vs $60 \%$, $P=0 \cdot 0001)$. This 30 -day mortality difference remained significant even after adjustment for age, systolic blood pressure, infarct location, and heart rate $(P=0 \cdot 007)$. The mortality difference also tended to persist for patients in the two trials treated with t-PA alone: $136 / 219(62 \cdot 1 \%)$ in GUSTO-III vs $338 / 610(55 \cdot 4 \%)$ in GUSTO-I, $P=0 \cdot 086$. Overall mortality rates in subgroups of patients undergoing coronary angiography, angioplasty, bypass surgery and intra-aortic balloon counterpulsation were however similar in the two trials.

Other end-points, including reinfarction (14 vs 11\%, $P=0.013)$ and recurrent ischaemia (35 vs $27 \%$, $P=0 \cdot 00001$ ), were also higher in the GUSTO-III cardiogenic shock population. There was a significantly shorter length of stay for cardiogenic shock survivors in GUSTO-III ( $9 \cdot 0$ vs 14 days, $P=0 \cdot 0001)$.

Table 5 compares mortality with cardiogenic shock at U.S. and non-U.S. centres. The mortality rate for U.S. 
Table 4 Mortality rates in GUSTO-I vs GUSTO-III

\begin{tabular}{llcr}
\hline Patient group & $\begin{array}{c}\text { GUSTO-I } \\
\%(\mathrm{n})\end{array}$ & $\begin{array}{c}\text { GUSTO-III } \\
\%(\mathrm{n})\end{array}$ & $P$ value \\
\hline Overall 30-day mortality rates & $54(2814)$ & $62(695)$ & $0 \cdot 001$ \\
Overall 1-year mortality rates & $60(2814)$ & $69(695)$ & $0 \cdot 001$ \\
Mortality, tPA* & $55(610)$ & $62(219)$ & $0 \cdot 086$ \\
Mortality, angiography* & $32(1326)$ & $36(270)$ & $0 \cdot 182$ \\
Mortality, angioplasty* & $32(558)$ & $37(131)$ & $0 \cdot 280$ \\
Mortality, bypass surgery* & $29(337)$ & $42(169)$ & $0 \cdot 988$ \\
Mortality, IABP* & $45(716)$ & $0 \cdot 446$ \\
\hline
\end{tabular}

$\mathrm{n}=$ number of patients in group.

*30-day mortality in patients undergoing specified treatment/procedure.

$\mathrm{IABP}=$ intra-aortic balloon counterpulsation .

Table 5 Mortality in subgroups of cardiogenic shock patients based on therapy received and location

\begin{tabular}{llccc}
\hline 30-day mortality & $\begin{array}{c}\text { G-I U.S. } \\
\%(\mathrm{n})\end{array}$ & $\begin{array}{c}\text { G-I non-U.S. } \\
\%(\mathrm{n})\end{array}$ & $\begin{array}{c}\text { G-III U.S. } \\
\%(\mathrm{n})\end{array}$ & $\begin{array}{c}\text { G-III non-U.S. } \\
\%(\mathrm{n})\end{array}$ \\
\hline Overall & $50(1891)$ & $64(923)$ & $53(271)$ & $68(424)$ \\
Angioplasty* & $30(482)$ & $45(76)$ & $29(87)$ & $52(44)$ \\
Bypass surgery & $28(295)$ & $36(42)$ & $31(49)$ & $25(28)$ \\
IABP & $44(654)$ & $55(62)$ & $40(127)$ & $48(42)$ \\
\hline
\end{tabular}

$\mathrm{n}=$ number of patients in group.

G-I=GUSTO-I; G-III = GUSTO-III; IABP=intra-aortic balloon counterpulsation.

*Angioplasty of culprit or non-culprit vessel.

cardiogenic shock patients in GUSTO-III was 53\% compared with $50 \%$ in GUSTO-I $(P=0 \cdot 269)$. The mortality rate for the group of U.S. patients receiving angioplasty was $29 \%$ in GUSTO-III and $30 \%$ in GUSTO-I $(P=0 \cdot 86)$. Similarly, U.S. patients receiving bypass surgery had a $31 \%$ mortality rate in GUSTO-III and a $28 \%$ rate in GUSTO-I $(P=0 \cdot 648)$. Although the overall mortality rate in the non-U.S. patients was higher than that for U.S. patients in both GUSTO-III and GUSTO-I (68\% and $64 \%$, respectively) they remained similar over the decade $(P=0 \cdot 132)$. Angioplasty in this non-U.S. population had a mortality rate of $52 \%$ in GUSTO-III compared with $45 \%$ in GUSTO-I $(P=0.426)$. The bypass surgery mortality in this group was $25 \%$ in GUSTO-III and $36 \%$ in GUSTO-I $(P=0 \cdot 344)$.

Mortality rates for cardiogenic shock patients with various thrombolytic regimens are presented in Fig. 3. The lowest mortality was seen in the group receiving streptokinase in GUSTO-I. In the GUSTO-III cardiogenic shock population, the mortality rates with reteplase and t-PA were equivalent $(62 \%)$.

\section{Discussion}

The GUSTO-I and GUSTO-III trials provide us insight on the incidence, management and outcomes with cardiogenic shock complicating thrombolytic treated STelevation myocardial infarction. While the baseline risk of patients with myocardial infarction and cardiogenic shock appears to be increasing, overall rates of revascularization and intra-aortic balloon counterpulsation support have remained static. Consequently mortality rates with cardiogenic shock have not declined.

\section{Patient characteristics}

Age is the major determinant of 30-day mortality following acute myocardial infarction ${ }^{[12]}$. Although elderly patients were excluded from early thrombolytic trials, the relative efficacy of thrombolysis in this population is now clearly established ${ }^{[13]}$. This has expanded the role of thrombolysis to a higher-risk population with their increasing inclusion in clinical trials. The baseline risk for patients suffering acute myocardial infarction is also increasing, mainly due to an ageing population as well as improved therapies for primary and secondary treatment of atherosclerotic coronary artery disease. Patients developing cardiogenic shock in GUSTO-III were significantly older than their counterparts in GUSTO-I, and they had a higher baseline risk profile with more diabetes, hypertension, previous myocardial infarction, and index anterior wall infarction. In keeping with this increased risk, presentation Killip class was also significantly higher for GUSTO-III cardiogenic shock patients. This higher risk profile is not solely restricted to patients who developed cardiogenic shock; in the overall 


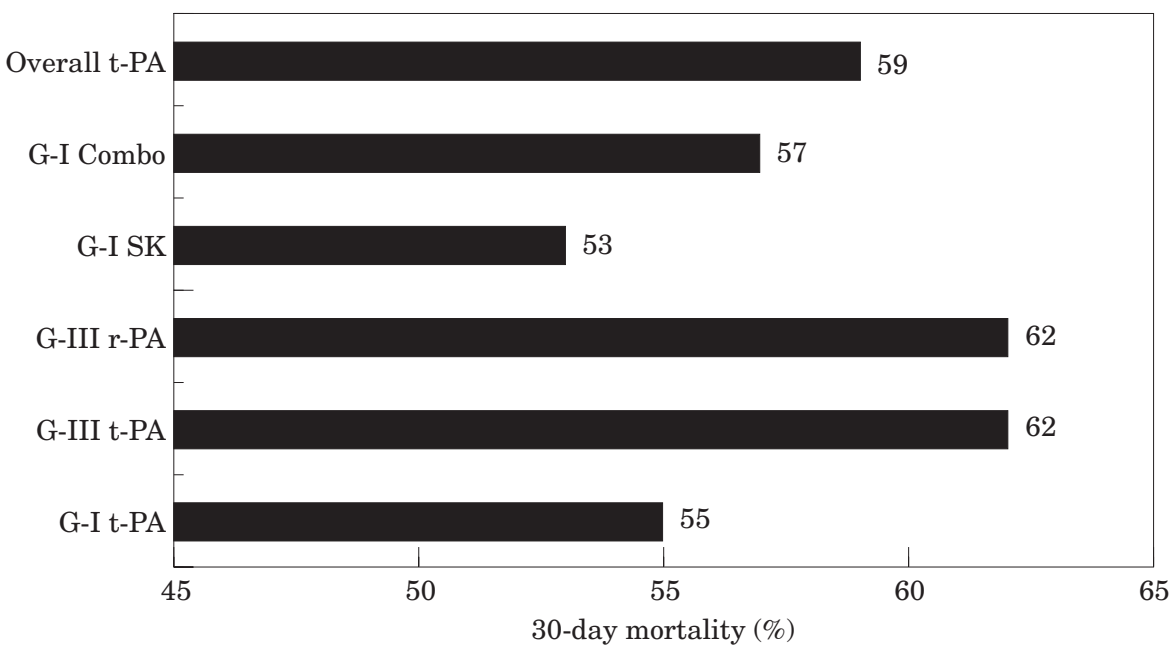

Figure 3 The mortality rate with various lytic regimens used for cardiogenic shock subjects in the GUSTO-I and GUSTO-III trials is illustrated here. The combination group (G-I Combo) represents the GUSTO-I arm treated with a combination of streptokinase and t-PA. (G-I = GUSTO-I; G-III = GUSTO-III; SK = streptokinase).

GUSTO-III study population, median age was greater and anterior infarction more common than in GUSTO-I.

\section{Incidence}

In light of the higher risk profile of patients in GUSTOIII and the overall greater mortality seen in that trial, the reported decrease in the incidence of cardiogenic shock in GUSTO-III may be perceived as a paradox. This decline was not the result of time to treatment, which was similar in the two studies, nor explained by the overall revascularization rates, which were comparable. The definition of cardiogenic shock was also uniform throughout the duration of the two studies.

Unlike GUSTO-I, a significant difference in the incidence of cardiogenic shock in non-U.S. and U.S. centres is no longer apparent. This is because the reported incidence of cardiogenic shock appears to have declined in the U.S.A. while remaining relatively static in nonU.S. centres. This decreased incidence of cardiogenic shock in the U.S.A. seen in GUSTO-III is encouraging but requires critical scrutiny. Incidence rates for cardiogenic shock in non-U.S. centres both in GUSTO-I and GUSTO-III, and U.S. centres in GUSTO-III appear identical. Placed in this context, the high U.S. incidence of cardiogenic shock in GUSTO-I may perhaps be aberrance. It is also plausible that the subjective criteria for diagnosing cardiogenic shock in the U.S.A. may have tightened over time. A referral bias towards primary angioplasty in the U.S.A. may have also contributed towards this observation. In contrast, a community-based study recently reported that the incidence of cardiogenic shock in the U.S.A. was unchanged in the $1990 \mathrm{~s}^{[14]}$
Closer observation also reveals that the proportion of patients with cardiogenic shock enrolled in the U.S.A. differed significantly between the two studies. The U.S. contribution towards GUSTO-III was significantly lower than that in GUSTO-I. Thus the declining incidence of cardiogenic shock in the U.S.A. coupled with decreased U.S. representation appears to have led to an overall decreased incidence of cardiogenic shock in GUSTO-III.This difference in representation may also serve to explain many of our observations.

In an analysis of the GUSTO-I cardiogenic shock population, Holmes et al. showed a significantly lower mortality for patients treated in the U.S.A. compared with non-U.S. locations ${ }^{[15]}$. A better outcome for cardiogenic shock subjects enrolled in the U.S.A. is again evident in GUSTO-III. As hypothesized in GUSTO-I, the geographical disparity in mortality rates may have been due to the greater use of diagnostic, invasive and therapeutic intervention in the U.S.A. The lower riskprofile of U.S. cardiogenic shock patients as observed in GUSTO-I may have also contributed in part to this favourable outcome. Thus, a decreased U.S. representation in the GUSTO-III population may have contributed towards the overall increased mortality with cardiogenic shock. This is further supported by the fact that overall subgroup mortality at non-U.S. and U.S. sites in GUSTO-I and GUSTO-III did not change significantly between the two studies.

\section{Procedures}

The negative publicity for the pulmonary artery catheter coupled with the widespread use of echocardiography may have contributed toward the observed decline in the use of the pulmonary artery catheter; a trend that was 
more marked at U.S. centres ${ }^{[16]}$. Despite experimental evidence to suggest both a synergistic role with thrombolysis in patients with hypotension ${ }^{[17,18]}$ and a trend toward lower mortality ${ }^{[19-21]}$, overall intra-aortic balloon counterpulsation use has not increased and is still used in only a minority of patients with cardiogenic shock. This appears to result from infrequent utilization of intra-aortic balloon counterpulsation at non-U.S. centres, as intra-aortic balloon counterpulsation use in the U.S.A. significantly increased during the study period.

The overall rate of diagnostic coronary angiography was also significantly lower in GUSTO-III. While rates of angiography increased in the U.S., non-U.S.A. rates remained static during the study period. This non-U.S. trend is consistent with the overall less aggressive approach towards cardiogenic shock. It may, however, also reflect more co-morbidity and severe disease resulting in greater selectivity for angiography ${ }^{[21]}$. Overall rates of angioplasty and bypass surgery were similar in the two studies. However, marked differences in revascularization rates between non-U.S. and U.S. sites persist. Rates of angioplasty in the U.S.A. increased from GUSTO-I to GUSTO-III while bypass surgery remained similar. In contrast, rates of angioplasty and bypass surgery remained low at non-U.S. sites. As a result of increased non-U.S. representation, however, the net population receiving these procedures did not change over the study period.

\section{Outcome}

Thirty-day mortality for patients with cardiogenic shock was significantly higher in GUSTO-III than in GUSTO-I. Rates of reinfarction and recurrent ischaemia were also significantly higher in the GUSTO-III cardiogenic shock population. While patient characteristics may have contributed in part, the difference remained statistically significant after adjustment for major baseline variables. In a multivariate analysis of the GUSTO-I trial, age and systolic blood pressure were the only factors more strongly associated than geographical location with increased mortality ${ }^{[15]}$. As noted, a decreased U.S. representation in a higher-risk study group may have contributed to this observation. The threshold for angioplasty is clearly different at non-U.S. and U.S. locations, as indicated by the increased mortality seen for patients receiving angioplasty in non-U.S. locations. This suggests that, unlike in the U.S.A., only a select group at highest risk undergo angioplasty at the latter sites.

Previous thrombolytic studies have also suggested a lower mortality for streptokinase compared with t-PA for patients with established cardiogenic shock ${ }^{[22]}$. This did not explain our observations, as mortality also tended to remain higher for patients with cardiogenic shock treated with front-loaded t-PA in GUSTO-III compared with GUSTO-I. Our observations highlight that morbidity with cardiogenic shock did not decrease for thrombolytic-treated patients through the 1990s. However, the static U.S. mortality rates in spite of increasing patient risk is cause for optimism.

\section{Implications}

We did not observe a decrease in mortality from cardiogenic shock with time between the two GUSTO studies. Overall rates of revascularization and intra-aortic balloon counterpulsation, however, were similar in these two trials. This is in contrast to the Worcester study that recently reported a decline in mortality with cardiogenic shock starting during 1993-95 and extending through $1997^{[14]}$. It must be noted that the decline in mortality seen in this community study paralleled an increased utilization of revascularization and intra-aortic balloon counterpulsation. Thus, in the setting of cardiogenic shock, there appears to be a direct and positive relationship between aggressive revascularization therapy and survival. This is further supported by the NHLBIsupported prospective SHOCK trial which recently reported a $9 \%$ absolute mortality benefit at 30 days for an emergency revascularization strategy over one of initial medical stabilization ${ }^{[23]}$. Although this difference in mortality did not reach statistical significance, 6-month and 12-month follow-up demonstrated a survival benefit with an aggressive early revascularization approach, especially in those $<75$ years of age ${ }^{[24]}$. The relationship between revascularization rates and outcome with cardiogenic shock is, however, not linear. A significant increase in U.S. angioplasty rates in GUSTO-III over GUSTO-I did not translate into a significant mortality benefit. Further benefit is perhaps nullified by the presence of a moribund subgroup beyond the point of therapeutic salvage, or patients in whom delayed procedures may have increased the risk without benefit.

As evidenced by the GUSTO trials, our overall performance in the management of cardiogenic shock in the 1990s remained inadequate and deserves intense scrutiny. Our observations suggest an under-utilization of interventional procedures in the setting of cardiogenic shock. This is especially true at non-U.S. sites. Overall mortality with shock remains high. Novel new therapies to further protect and salvage acutely ischaemic myocardium need to be explored.

We wish to thank John Daniel for his invaluable role in editing this manuscript.

\section{References}

[1] The GUSTO Investigators. An international randomized trial comparing four thrombolytic strategies for acute myocardial infarction. N Engl J Med 1993; 329: 673-82.

[2] The GUSTO Angiographic Investigators. The comparative effects of tissue plasminogen activator, streptokinase, or both on coronary artery patency, ventricular function, and survival after myocardial infarction. N Engl J Med 1993; 329: 1615-22.

[3] Simes RJ, Topol EJ, Holmes DR et al. Link between the angiographic substudy and mortality outcomes in a large 
randomized trial of myocardial reperfusion: importance of early and complete infarct artery reperfusion. Circulation 1995; 91: 1923-8.

[4] Meinertz T, Kasper W, Schumacher M et al. The German multi-center trial of anisoylated streptokinase activator complex versus heparin for acute myocardial infarction. Am J Cardiol 1988; 62: 347-51.

[5] Wilcox RG, Olsson CG, von der Lippe G et al. Trial of tissue plasminogen activator for mortality reduction in acute myocardial infarction (ASSET). Lancet 1988; ii: 525-30.

[6] Holmes DR Jr, Bates ER, Kleiman NS et al. Contemporary reperfusion therapy for cardiogenic shock: the GUSTO-I trial experience. J Am Coll Cardiol 1995; 26: 668-74.

[7] Col NF, Gurentz JH, Alpert JS, Goldberg RJ. Frequency of inclusion of patients with cardiogenic shock in clinical trials. Am J Cardiol 1994; 73: 149-57.

[8] The GUSTO-III Investigators. A comparison of reteplase with alteplase for acute myocardial infarction. N Engl J Med 1997; 337: 1118-23.

[9] The ISIS-3 Investigators. A randomized comparison of streptokinase vs tissue plasminogen activator vs anistreplase and of aspirin plus heparin vs aspirin alone among 41299 cases of suspected acute myocardial infarction. Lancet 1992; 339: $753-$ 70.

[10] Gruppo Italiano per lo Studio della Streptochinasi nell'Infarto Miocardico (GISSI). Effectiveness of intravenous thrombolytic therapy in acute myocardial infarction. Lancet 1986; $\mathrm{i}$ : 397-402.

[11] Granger CB, Hirsch J, Califf RM et al. Activated partial thromboplastin time and outcomes after thrombolytic therapy for acute myocardial infarction; results from the GUSTO-I trial. Circulation 1996; 93: 870-8.

[12] Lee KL, Woodlief LH, Topol EJ et al. Predictors of 30 day mortality in the era of reperfusion for acute myocardial infarction. Results from an international trial of 41,021 patients. GUSTO-1 Investigators. Circulation 1995; 91: 1659-68.

[13] FTT Collaborative Group. Indications for fibrinolytic therapy in suspected acute myocardial infarction: collaborative overview of mortality and major morbidity results from all randomized trials of more than 1000 patients. Lancet 1994; 343: $311-22$.
[14] Goldberg RJ, Samad NA, Yarzebski J, Gurwitz J, Bigelow C, Gore JM. Temporal trends in cardiogenic shock complicating acute myocardial infarction. N Engl J Med 1999; 340: $1162-8$.

[15] Holmes DR Jr, Califf RM, Van de Werf et al. Differences in countries use of resources and clinical outcome for patients with cardiogenic shock after myocardial infarction. Lancet 1997; 349: 75-8.

[16] Connors AF Jr, Speroff T, Dawson NV et al. The effectiveness of right heart catheterization in the initial care of critically ill patients. J Am Med Assoc 1996; 18: 889-97.

[17] Prewitt RM, Gu S, Schick U, Ducas J. Intraaortic balloon counterpulsation enhances coronary thrombolysis induced by intravenous administration of a thrombolytic agent. J Am Coll Cardiol 1994; 23: 784-8.

[18] Gurbel PA, Anderson RD, MacCord CS et al. Arterial diastolic blood pressure augmentation by intraaortic balloon counterpulsation enhances the onset of coronary reperfusion by thrombolytic therapy. Circulation 1994; 89: 361-5.

[19] Anderson RD, Ohman EM, Holmes DR Jr et al. Use of intraaortic balloon counterpulsation in patients presenting with cardiogenic shock: observations from the GUSTO-I study. J Am Coll Cardiol 1997; 30: 708-15.

[20] Waksman R, Weiss AT, Gotsman MS et al. Intraaortic balloon counterpulsation improves survival in cardiogenic shock complicating acute myocardial infarction. Eur Heart J 1993; 14: 71-4.

[21] Hochman JS, Boland J, Sleeper LA et al. Current spectrum of cardiogenic shock and effect of early revascularization on mortality. Results of an international registry. Circulation 1995; 91: 873-81.

[22] International Study Group. In hospital mortality and clinical course of 20861 patients with suspected acute myocardial infarction randomized between alteplase and streptokinase with or without heparin. Lancet 1990; 336: 71-5.

[23] Hochman JS, Sleeper LA, Webb JG et al. Early revascularization in acute myocardial infarction complicated by cardiogenic shock. N Engl J Med 1999; 341: 625-34.

[24] Hochman JS, Sleeper LA, Webb J et al. Effect of early revascularization for cardiogenic shock on 1 year mortality; the SHOCK trial results (Abstr). Circulation 1999; 100: I-369. 